\title{
Impact of Prestigious Indicators on Sustainable Growth of Small and Medium-Sized Enterprises in Pakistan
}

\author{
Shoaib Ali ${ }^{1 \rtimes}$ \\ Farooq Azam ${ }^{2}$ \\ Hafiz Muhammad Naveed ${ }^{3}$ \\ Waqar Abid ${ }^{4}$
}

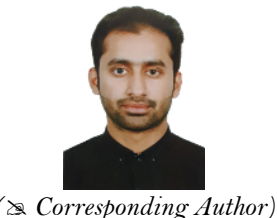

'School of Management, Jiangsu University, Zhenjiang, China. Email:Shooaibali6@gmail.com Tel: +8618651289296.

Faculty of Commerce, Hailey College of Commerce, University of the Punjab, Lahore Pakistan. Email: lukeblcu@hotmail.com Tel: +923334331313

${ }^{s}$ School of Finance and Economics, Jiangsu University, China.

Email:Hafiznaveed778@gmail.com Tel:+8618651289309

'School of Economics and finance, Xi'an Jiaotong University, P.R. China.

Email:Waqarabid64@gmail.com Tel:+9203084421644

\section{Abstract}

This study aims to examine the prestigious indicators influencing the sustainable growth of Small and Medium Enterprises (SME's) in Pakistan. This research is comprised of primary data. The evidence for this analysis was collected through a standardized questionnaire. The study population structure is extracted from Pakistan's Punjab province. Sample selection is performed employing a random sample technique. The set of questionnaires were 200 circulated but 25 inadequate questionnaires were excluded. The research employed descriptive statistics and the process of regression to evaluate significant indicators concerning Pakistan's SMEs. The study findings demonstrate that the most imperative indicators associated with the sustainable growth of Pakistan's SME's are government funding, access to credit, and technology awareness turn out to have been vital indicators. Furthermore, results revealed that Pakistan SME's are not riskfocused. The research findings may enable business owners to identify essential indicators that compete with a considerable function in their enterprise's growth. The study indicates authorities should consider the results when implementing regulation that can give a sense which would be practicable for the sustainable growth of Pakistan's SMEs.

Keywords: Government funding, Access to credit, Technology awareness, Small, Medium enterprises, Sustainable growth, Pakistan. JEL Classification: H11, L32, Ooo, Qo1.

Citation | Shoaib Ali; Farooq Azam; Hafiz Muhammad Naveed; Waqar Abid (2020). Impact of Prestigious Indicators on Small and Medium-Sized Enterprises Sustainable Growth in Pakistan. Asian Journal of Economics and Empirical Research, 7(2): 251-257. History:

Received: 14 July 2020

Revised: 18 August 2020

Accepted: 21 September 2020

Published: Otober 2020

Licensed: This work is licensed under a Creative Commons

Attribution 3.0 License (cc)

Publisher: Asian Online Journal Publishing Group
Acknowledgement: All authors contributed to the conception and design of the study.

Funding: This study received no specific financial support

Competing Interests: The authors declare that they have no conflict of interests.

Transparency: The authors confirm that the manuscript is an honest, accurate, and transparent account of the study was reported; that no vital features of the study have been omitted; and that any discrepancies from the features of the study have been omitted;
study as planned have been explained.

Ethical: This study follows all ethical practices during writing.

\section{Contents}

1. Introduction

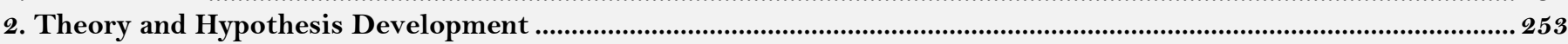

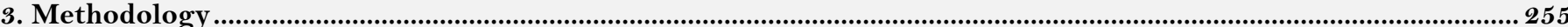

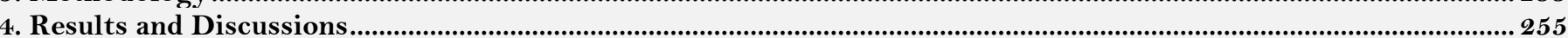

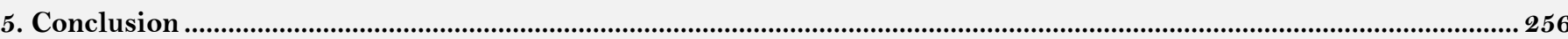

References 


\section{Contribution of this paper to the literature}

This study contributes to existing literature by examining the prestigious indicators influencing the sustainable growth of Small and Medium Enterprises (SME’s) in Pakistan.

\section{Introduction}

The small-and-medium-sized enterprises (SME's) business sector is an important part of any economy. The SME's enterprise sector has made tremendous improvements to the financial and social quality of life-being of people worldwide and more specifically, emerging regions of the world in developing and underdeveloped economies. It has a substantial part of job creation and the main contributor to a country's gross domestic production, development, and exports (Loewe et al., 2013). The SME's sectors are effective in promoting entrepreneurial potential and also maintain grass-roots sustainable economic development, thus supporting the country's viable and sustainable growth.

As well as, SME's expansion can contribute to economic change and positive flexibility. In particular, in the instance of Asia's developing economies especially, SMEs are contributing greater job opportunities (Badar \& Rahman, 2015; Harvie, 2010). SME's provide employment opportunities for millions of underprivileged groups, as well as helping to improve skill rates for low-skilled or unskilled workers. SME's also facilitates society's upward growth by encouraging poor or oppressed communities including such women, the elderly, newcomers, cultural or racial communities, and the impaired to build their opportunities for economic participation. Hence, SMEs serve as a valuable mechanism for reducing poverty and sustainable growth, but not entirely in developing and low-income economies (OECD \& WBG, 2015). The growth and sustainability of SMEs are essential for the measure of the developing countries' development.

SME's are the growth drivers for developing countries. The substantial study was carried on the major importance of the SME's. Meanwhile, research on the problem and development of the SME's sector in Pakistan is slowing down away. The small and medium enterprises development authority (SMEDA) is a government body in Pakistan that has worked to grow the SME's infrastructure during the last years. Many of SME's are not authorized with government departments and have no connection to get SMEDA funding or help. While SMEDA worked over all years, advancement against SME's expansion but it was constrained. This research would provide support for the importance of SMEs and would examine the prestigious factors that lead to SME's sustainable growth in Pakistan.

In Pakistan, SME's have the ability in the expansion of the agriculture and food field, because they can make more effective use of sufficient resources and produce goods that are internationally appropriate which gives ground to export earnings. SMEs in Pakistan face many difficulties, such as access to financial services, lack of technological understanding, and information technology training. These challenges raise the need for adequate assistance to SME's sustainable growth (Jamali, Anka, \& Khooharo, 2010). The SMEDA worked in Pakistan to encourage the SME's, but primarily focused on upper-income sectors, as mostly Pakistani SME's are in the lowerincome sectors (Kureshi, Qureshi, \& Sajid, 2010). The SMEDA and small business finance corporations (SBFC) support to SME's in Pakistan in accessing credit funding but insufficient government initiatives are inadequate and ineffective tax regulations are the main obstacles to the restricted growth (Shah, Mehmood, Hashmi, Shah, \& Shaikh, 2011a).

Some earlier studies critically evaluated the issues that influence the economic expansion of SME's in other emerging countries such as India and Malaysia. The research applicable in Pakistan and investigated the impacts of a few attributes in the overall assessment of the sustainability of SMEs in Pakistan, through an individual level. Several other studies have explored whether major contributing factors are suitable for enterprises, or if they are related to enterprise features. This study emphasizes the impact of prestigious indicators on SME's sustainable growth in Pakistan, and explores the indicators that lead to sustainable development.

This research would convey the essence of emphasizing the factors which are influencing the growth of SMEs in Pakistan. Firstly, the study findings would make it convenient for policymakers to create a sustainable climate by policy development that will promote the growth of SMEs in Pakistan. Secondly, this is an opportunity to increase new knowledge regarding empirical information to Pakistan's SME sector.

However, this paper may help SME's owners to identify the effecting indicators of business development which can take effective action for the sustainable growth of Pakistan. Pakistan's SME's are very valuable for its economic growth. Due to restricted exposure and lack of knowledge, they don't get the help as they needed. Research proof on the growth of SMEs is scarce and numerous studies on this field are still required. The decisionmakers must have a clear understanding of the issues that impact the growth of SMEs in Pakistan. This research emphasizes on identifying the indicators affecting the sustainable growth of Pakistan SME's. The current study further explores the impacts of learning, market growth challenges, and the implementation of new technologies in SME's growth.

The Figure 1 theoretical framework analysis is built based on reviewing important indicators that can promote SME's sustainable growth in Pakistan. It has proposed a market-oriented economy focused on a sustainable regulation and legal structure where industries can roam freely. Throughout such a way, SMEs' component of pressure exposure will decline. Learning how to handle associated with SME's practices. This will also lead to the growth of the enterprises and eventually promote the growth of SMEs through policy funding and support programs for access to credit and the adoption of technology awareness (Chowdhury, 2007). The research is also applied to the system that contains marketing complications or challenges which need to be addressed for promoting SMEs internationally to raise bank deposits to concentrate on effective marketing. However, the main objective to examine prestigious indicators that influence the sustainable growth of SMEs in Pakistan. 


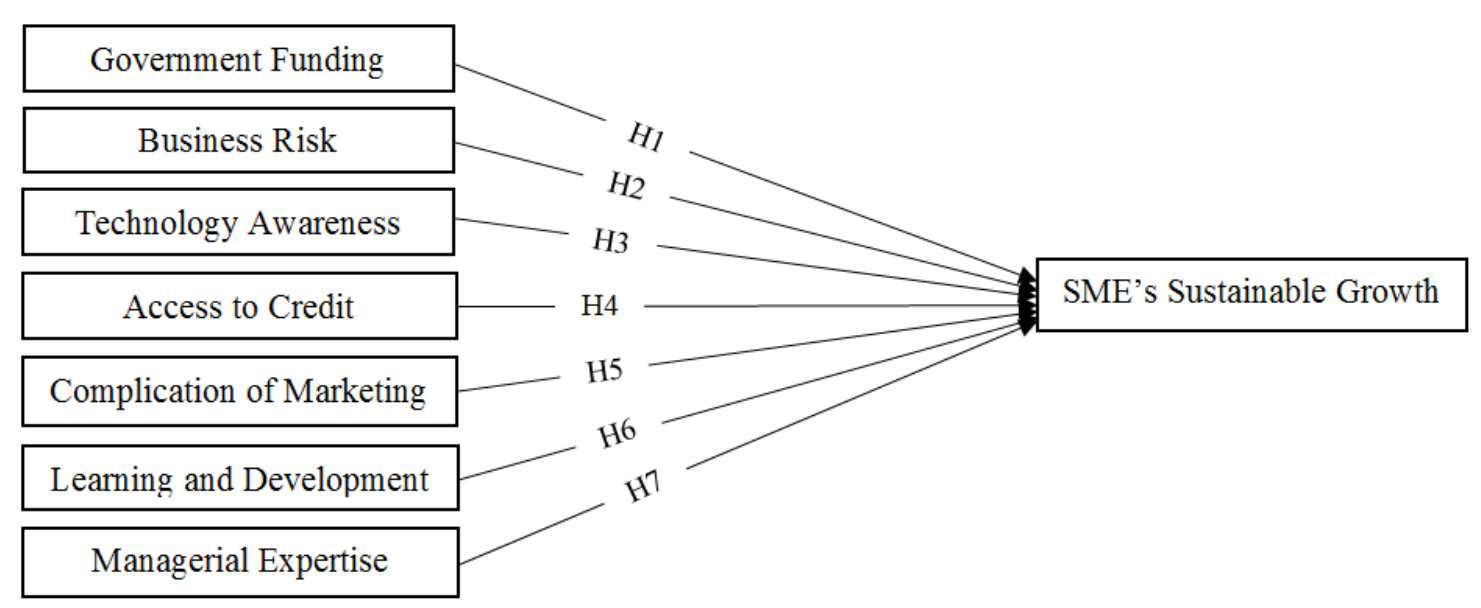

Figure-1. Theoretical framework.

\section{Theory and Hypothesis Development}

\subsection{SME's Sustainable Growth}

SME's are now becoming extremely aware of the effect of their public identity and their interaction with multistakeholders in reaction to regulatory growth and environmental intense oversight of SME's activities regarding sustainability challenges (Tonello, 2011). SME's is a substantial strength in economic growth and development, are shorter in volume and adaptable in the pattern, capable of responding quickly to market adjustments, meeting evergrowing and differentiated requirements for cultural utilization, and are still in pursuit of promoting the specialization-based collaboration of large-scale social output. In addition, SME's could continue driving the highspeed growth of the state and economy and perform a distinctive part in forming jobs, boosting marketplaces, alleviating poverty for people, and sustaining economic stability. However, to accomplish the rapid sustainable growth of SMEs, they need to evaluate those indicators that can significantly maintain and develop the growth of SMEs in Pakistan.

The role and development of SMEs in emerging country growth are key. As in Pakistan SME's companies make up a significant part of the market and makeup to 80 percent of employment. As competed with the largescale business area, the growth prospects of SMEs are greater (Chowdhury, 2007). While Pakistan's SMEs do not make significant participation in GDP, but their function is very significant in contexts of job creation, the efficient use of scarce resources, the chance to afford export earnings, and the capacity to act as an entity for future entrepreneurs. Hence, SMEs are valuable with quite a unique character as less financing, easy handling, fast produce, and instant adherence to changes in the business environment (Jamali et al., 2010).

\subsection{Government Funding}

SMEDA is already continued working for the advancement of the SME's sector in the last 15 years and it has not been able to create adequate economic growth. To encourage this field, government departments and other government bodies have to devise effective ways in form of loan or funding scheme programs which should go hand in hand with the SMEDA plan. There is a positive connection between government support for SME's development (Abrar-ul-Haq, Jali, \& Islam, 2015). Furthermore, through promoting SME's practices, it would contribute to alleviating poverty and may also result in significant with foreign exchange earnings.

Although many Pakistani SMEs has not paid much attention to having brought in sustainability practices in their industries, due to various their constrained resources. Creating and implementing government regulations that help SMEs in designing appropriate structures will solve this issue. Many studies have stressed that government funding is the key factor in Pakistan's SME's sustainable growth.

H1: Government funding is positively associated with SME's sustainable growth.

\subsection{Business Risk}

Another component which impacts on SME's growth is indeed the risk element. Overall risk (company as well as financial risk) could be an aspect along which there may be a funding disparity. The financial risks of a company (that also concentrates on the operations of a company), is the ambiguity of the company's return over its resources (Trovato \& Alfò, 2006). In comparison, financial risks exist when a company uses borrowing (i.e., financial collateral). For these situations, the business takes extra obligation for servicing the debt that collects interest timely payments. The business's failure to pay interest charges or repayment of principal would fail that may proceed in foreclosure.

Ntakobajira (2013) argued that financial institutions continue to attribute a high risk to SME's and are thus unable to allocate credit to small businesses. The loss statistics of small businesses are comparatively high due to the inadequate scale an underlying exposure to market volatility. Even by their existence these businesses are still relatively stable and often neglect a financial status. Furthermore, businesses and managerial failures, poorer quality governance, and an absence of sufficient accounting systems can negatively impact the transparency and quality of SME's information about their reimbursement potential. There is still a need to tackle business risk and improve SME's growth in Pakistan.

H2: Business risk is positively associated with SME's sustainable growth.

\subsection{Technology Awareness}

Implementing advanced manufacturing technology may be an approach to resolve product demand by higher productivity. Throughout this context processes such as increased performance per unit and reduction of inventory levels via higher operational volumes through the introduction of the Overall amount have been established. Increased production and timely delivery are important if businesses are to improve their performance efficiency. 
This research also stated the probability of failures of technologies in Pakistan's lack of experience, education, support, funding, and contribution to adoption (Marri, Gunasekaran, \& Sohag, 2007). The growth of SMEs will also be reinforced by numerous government development programs in obtaining access to financial and implementing new technology (Chowdhury, 2007).

Services vendors should encourage the technology and dynamic challenges of SME's producing products and fair need for outside sources, i.e. promoting the transformation and use of suitable technology in SMEs which would lead to SMEs' sustainable growth. There is a relatively positive relation of technology advancement and SME's (Jamali et al., 2010).

H3: Technology awareness is positively associated with SME's sustainable growth.

\subsection{Access to Credit}

Many SMEs businesses in Pakistan are classified as microstructure and many SMEs employed less than 50 workers since they failed to expand their operational activities to boost their position as a stable business. The main reason behind this issue is the lack of access to credit organizations in Pakistan (Bano, 2008). The microfinance banking institutions are the most determined institution which works access to credit to SME's while the requirements and interest rate are not favorable to SME's. Limited access to credit is a big issue for the sustainable growth of SMEs. The SMEDA or SBFC is the only inadequate source for access to credit provision. higher interest levels, heavy collateral criteria, and insufficient management are the key reasons for restricted access to credit (Jamali et al., 2010). The key explanation for the restricted growth of SMEs is not only access to credit while an inflexible government taxation system is also a significant factor (Shah, Mehmood, Hashmi, Shah, \& Shaikh, 2011b). Naqvi (2011) explained that large risk rates applied to SMEs have reflected in the high cost of borrowing for financial credit.

H4: Access to credit positively associated with SME's sustainable growth.

\subsection{Complication of Marketing}

The research survey in Bangladesh as well discovered that financial system problems, government regulations, laws and legal facilitate, political, cultural, development, and skills are the major limitations to grow the SME's, as well as the research, has recommended a mechanism to address these to boost up the SME's growth. The research also proposed that corruption should be minimized to build a healthy atmosphere for SMEs to function and develop in a challenging economic environment (Chowdhury, 2007).

Indonesia's research analysis has defined marketing know-how, technologies, qualified quality management, promoting federal regulations, adequate funds, and marketing complications or challenges as the key drivers fostering SME growth in Indonesia. Even the results of this research are relevant for many other developing economies since SME's are an invaluable source of growth for the economy of every developing economy as well as the outcomes will also support lawmakers develop policies that support the growth of the SME in their country (Tambunan, 2011).

H5: Complications of marketing positively associated with SME's sustainable growth.

\subsection{Learning and Development}

The investigator has studied the disparity between manager attributes of low-performing and high-performing businesses through using safety metrics such as product sales. The findings revealed that schooling, community-tofamily transitions, behaviors that include electronic technology, and investment rates significantly impact the performance of the business. But the standard of learning is the most feasible ownership function that serves as encouraging Pakistan's SME's element (Bhutta, Rana, \& Asad, 2008). Learning and development skills about how to run the enterprises and entrepreneurial ventures would also contribute to the SME's growth (Chowdhury, 2007). The business investors' analysis found that many people need the learning and skills to operate and lead the business. So, the absence of enterprise management expertise is a significant limitation in Nigeria's SME's growth (Okpara, 2011). Implementing technology often focuses on employees learning and development, so adequate learning and development are necessary to prevent employees' obstacles to creating new things for SMEs' growth. H6: Learning and development are positively associated with SME's sustainable growth.

\subsection{Managerial Expertise}

Pakistan's SME's are doing poorly and contingently regarding their potential operations. Providing competition will lead to product quality control becoming effective both domestically and globally. There is a discrepancy between understanding of the quality managerial expertise in Pakistan and their operation. The organizations that use quality control methods are positive about the efficacy of these methods. In addition, those who do not adopt are not involved in using these methods. Thus, many Pakistani SMEs have just not given great attention to attempting to bring managerial quality behaviors in their enterprises due to various their limited resources. Constructing regulatory standards that help SMEs in improving quality structures and solves these issues. Many other studies have emphasized that managerial expertise and federal funding is just the key element in Pakistan's growth of SME's (Kureshi et al., 2010).

H7: Managerial expertise positively associated with SME's sustainable growth.

The research also showed that cognitive and interpersonal abilities (behavior about risk, creativity, and selfrule), leadership education and competencies (financial services and workforce management), as well as the immediate forces (funding exposure and government assistance), are crucial growth drivers for SMEs (Benzing, Chu, \& Kara, 2009). The corruption leading from close to zero-quality service and has also failed SME's, though stressing that reduce training levels, lack of management understands exactly-how and learning result in big growth expense. Therefore, lawmakers need to strike a rebalancing between the obstacles that SME's face and the need to promote SME's growth. SMEs in Pakistan are confronting serious large obstacles and weak assistance. 


\section{Methodology}

\subsection{Sample and Data Collection}

This study is conducted to evaluate our hypothesis with an empirical assessment. This research is contained in primary data. The tool used in this study is a questionnaire that is adapted from Pakistan and Indonesian studies (Abrar-ul-Haq., Jali, \& Islam, 2015; Indarti \& Langenberg, 2004). The questionnaire for this study includes numerous explanatory indicators which could contribute to SME's sustainable growth in Pakistan. The study population structure is extracted from Pakistan's province Punjab. Sample selection is performed employing a random sample technique. The set of questionnaires were 200 circulated but 25 inadequate questionnaires were excluded. The final sample consisted of 175 effective questionnaires, which is participating in a 17.5 percent response rate. To settle the important indicators affecting the growth of SME's in Pakistan, SPSS statistics 21 is implied with regression.

\subsection{Questionnaire with Variables}

Table-1. Variables Development.

\begin{tabular}{|c|c|c|c|}
\hline Variables & Abbreviation & Types & Questionnaire (Likert scale $1-5$ ) \\
\hline $\begin{array}{l}\text { SME's sustainable } \\
\text { growth }\end{array}$ & $\mathrm{SG}$ & Dependent & $\begin{array}{l}\text { Sense of achievement with the net earnings growth; } \\
\text { Sense of achievement mostly with the time required to } \\
\text { get to breakeven point; Recognize the enterprise to be } \\
\text { good; consider enterprise is up warding. }\end{array}$ \\
\hline $\begin{array}{l}\text { Government } \\
\text { funding }\end{array}$ & GF & Independent & $\begin{array}{l}\text { Government funding is adequate; Conveniently got } \\
\text { enterprise license; There are no issues with } \\
\text { Government communication; Does government actions } \\
\text { have a beneficial effect on your enterprises. }\end{array}$ \\
\hline Business risk & $\mathrm{BR}$ & Independent & $\begin{array}{l}\text { Does enterprise take on added responsibility for risk of } \\
\text { taking debt financing; Enterprise's failure to pay } \\
\text { borrowing costs; More reliance on internal funds by } \\
\text { companies, }\end{array}$ \\
\hline $\begin{array}{l}\text { Technology } \\
\text { awareness }\end{array}$ & TA & Independent & $\begin{array}{l}\text { Sufficient installed technology to promote most other } \\
\text { production methods; Extant technology encourages } \\
\text { creativity; Conveniently maintainable extant } \\
\text { technologies; Modern technology to promote market } \\
\text { innovative behavior is achievable; Adopting modern } \\
\text { technology is boosting output. }\end{array}$ \\
\hline Access to credit & $\mathrm{AC}$ & Independent & $\begin{array}{l}\text { Previous capital is enough to keep and grow firm; If } \\
\text { necessary, could easily provide additional capital; Have } \\
\text { affordable substitute sources of access to credit }\end{array}$ \\
\hline $\begin{array}{l}\text { Complication of } \\
\text { marketing }\end{array}$ & $\mathrm{CM}$ & Independent & $\begin{array}{l}\text { The network of channel distribution; Business has } \\
\text { market potential; Marketing is not complicated and } \\
\text { also well designed to discover new for markets. }\end{array}$ \\
\hline $\begin{array}{l}\text { Learning and } \\
\text { development }\end{array}$ & $\mathrm{LD}$ & Independent & $\begin{array}{l}\text { Is professional training extremely important for } \\
\text { enterprise growth; Is formal learning development help } \\
\text { sound decision-making; Does formal education boost } \\
\text { market comprehension. }\end{array}$ \\
\hline $\begin{array}{l}\text { Managerial } \\
\text { Expertise }\end{array}$ & $\mathrm{ME}$ & Independent & $\begin{array}{l}\text { Management } \begin{array}{l}\text { expertise abilities are essential for } \\
\text { productive enterprise operation; }\end{array} \text { Have strong } \\
\text { management expertise experience; Have outstanding } \\
\text { interpersonal capabilities; Abilities in strategic } \\
\text { thinking are quite essential to enterprise achievement. }\end{array}$ \\
\hline
\end{tabular}

\section{Results and Discussions}

The inner reliability for the component is already verified for each build by measuring Cronbach's alpha. The calculated estimates indicate the accuracy of the data internally. The Cronbach's values for government funding, business risk, technology awareness, access to marking, the complication of marketing, learning and development, managerial expertise is $0.69,0.67,0.71,0.81,0.75,0.78$, and 0.87 respectively.

Table-2. Descriptive Statistics and Correlation Matrix

\begin{tabular}{c|c|c|c|c|c|c|c|c|c|c}
\hline Variables & Mean & SD & SG & GF & BR & TA & AC & CM & LD & ME \\
\hline SG & 5.30 & 0.84 & 1 & & & & & & & \\
\hline GF & 4.25 & 0.81 & $.615^{* *}$ & 1 & & & & & & \\
\hline BR & 3.66 & 0.79 & $.327^{* *}$ & $.436^{* *}$ & 1 & & & & & \\
\hline TA & 3.29 & 0.73 & $.414^{* *}$ & $.426^{* *}$ & $.827^{* *}$ & 1 & & & & \\
\hline AC & 3.42 & 0.92 & $.317^{*}$ & $.212^{*}$ & $.567^{* *}$ & $.420^{* *}$ & 1 & & & \\
\hline CM & 2.03 & 0.73 & $.128^{*}$ & .234 & $.124^{* *}$ & $.436^{* *}$ & $.344^{* *}$ & 1 & & \\
\hline LD & 2.90 & 0.82 & .033 & .262 & .124 & $.215^{*}$ & $.361^{*}$ & $.177^{* *}$ & 1 & \\
\hline ME & 3.50 & 0.79 & .435 & $.154^{*}$ & $.126^{* *}$ & $.381^{* *}$ & $.237^{* *}$ & $.345^{*}$ & $.241^{* *}$ & 1 \\
\hline Note:
\end{tabular}

* Correlation is significant at the 0.05 level (2-tailed).

Demographic statistics revealed that 72 percent were male participants, but only 28 percent were female. Their age was 25 percent between 25 and 35, 40 percent were between 35 and 45, 30 percent were between 45 and 55 and only 5 percent were above 55 . The educational background indicates that graduation was attained by 35 percent of participants, post-graduation was attained by 15 percent and secondary level or secondary level by 50 percent. 
Addressed the average value of each variable and the standard deviation. Correlations are measured to evaluate the variables which are dependent and explanatory. The results of the test demonstrate and explain in Table 2.

Table-3. Regression Coefficients.

\begin{tabular}{c|c|c}
\hline \multicolumn{3}{|c|}{ Table-3. Regression Coefficients. } \\
\hline Variables & Coefficients & t-value \\
\hline Constant $)$ & 0.186 & 1.090 \\
\hline $\mathrm{GF}$ & $0.056^{*}$ & 1.023 \\
\hline $\mathrm{TA}$ & $0.404^{*}$ & 10.72 \\
\hline $\mathrm{AC}$ & $0.190^{* *}$ & 8.312 \\
\hline $\mathrm{CM}$ & $0.051^{*}$ & 2.918 \\
\hline $\mathrm{LD}$ & $0.215^{*}$ & 1.430 \\
\hline $\mathrm{ME}$ & $0.085^{* *}$ & 1.073 \\
\hline $\mathrm{R}=0.85 \mathrm{~F}=159.26 \mathrm{P}=0.00$ & \\
\hline Note: * Significant at the 0.01 level, ** significant at the 0.05 level.
\end{tabular}

In Table 3 the amount of constant is 0.186 , which has a positive relationship with the predictor variable and it is empirically insignificant. While this study's $\mathrm{R}^{2}$ is 0.85 which indicates that the structure is important and explains a strong percentage of the hypothesis and the variability in predictor variables due to variables is about 85 percent. Throughout this particular scenario, explanatory variables (government funding, business risk, technology awareness, access to credit, a complication of marketing, learning and development, managerial expertise) decide around 0.85 SME's sustainable growth, as well as the corresponding portion, is influenced by other parameters that have not been addressed within that current research.

The very initial hypothesis is agreed that government funding has a positive and important association with the sustainable growth of SME's as the explanatory variable government funding coefficient value is 0.056. The second hypothesis (H2) that is business risk has been denied since the current research identified no meaningful association between sustainable growth of SMEs and fell out of model through employing step-wise regression testing.

Technology awareness (H3) is recognized, with a coefficient of 0.404 . The p-value of the explanatory variable indicates that the association regarding technology awareness and the sustainable growth of SMEs is essential. The hypothesis (H4) explanatory variable access to credit is supported and its coefficient value is 0.190 and the outcome is important at a degree of importance which is 1 percent. Hypothesis (H5) regarding explanatory variable complication of marketing and the coefficient value is 0.051 which is important at the point of importance which is 1 percent. The findings demonstrate a positive relationship between the complication of marketing and the sustainable growth of SMEs. Learning and development with a coefficient value of 0.215 have a positive connection with the sustainable growth of SMEs. Also agreed in the last hypothesis $(\mathrm{H} 7)$ regarding managerial expertise and it represents a coefficient value of 0.085 , which has a major impact on the sustainable growth of SMEs at a meaningful level.

\section{Conclusion}

SME's are development drivers for emerging economies such as Pakistan. SME's make a significant contribution to job advancement which is attributing to poverty mitigation. This research explored components that influence SME's in Pakistan including government funding, business risk, technology awareness, access to credit, a complication of marketing, learning and development, and managerial expertise. The findings also endorsed that all indicators rather than business risk perform an important function in the growth of SMEs. Business risk does not make a significant contribution well to the sustainable growth of SMEs in Pakistan because they are not business risk likely to judgment. A non-risk-taker is due to issues with power, or although they do not use complicated production operations.

Government funding, access to credit, and technology awareness turn out to have been vital indicators contributing to SME's growth. Pakistani SMEs do not rely mostly on selling their goods or commodities in a challenging world of today.

Numerous SME's owners are undereducated but the education system is presumed to have a major effect on the sustainable growth of SMEs. Many enterprises tend to use their resources instead of pursuing certain replacements. Pakistan's SME's have tremendous opportunities and can be investigated and encouraged through Pakistan. The government would accomplish it by implementing SME's growth conferences or seminars to much more effectively inform participants about SME's growth indicators. While most SME's in Pakistan are delighted about existing modest sales but therefore, not likely to expand their business.

\subsection{Future Research}

Potential studies upon that theme can determine by considering a bigger sample size because the findings of this study are restricted to Punjab province. Second, it is also important to investigate other indicators such as collateral requirement, availability information on finance, and cost of credit with interest that have not been studied.

\section{References}

Abrar-ul-Haq, M., Jali, M. R. M., \& Islam, G. M. N. (2015). Factors affecting small and medium enterprises (SMEs) development in Pakistan. American-Eurasian Journal of Agricultural \& Environmental Sciences, 15(4), 546-552.

Abrar-ul-Haq., M., Jali, M. R. M., \& Islam, G. M. N. (2015). Factors affecting small and medium enterprises (SMEs) development in Pakistan. American-Eurasian Journal of Agricultural \& Environmental Sciences, 15(4), 546-552.

Badar, I. A., \& Rahman, M. N. (2015). Contribution of ASEAN-6 SMEs to economic growth of ASEAN. Economics World, 3(11-12), 258-269. Available at: https://doi.org/10.17265/2328-7144/2015.1112.002.

Bano, M. (2008). Non-profit education providers vis-à-vis the private sector: comparative analysis of non-governmental organizations and traditional voluntary organizations in Pakistan. Compare, 38(4), 471-482. Available at: https://doi.org/10.1080/03057920701420932. 
Benzing, C., Chu, H. M., \& Kara, O. (2009). Entrepreneurs in Turkey: A factor analysis of motivations, success factors, and problems. Journal of Small Business Management, 47(1), 58-91. Available at: https://doi.org/10.1111/j.1540-627X.2008.00262.x.

Bhutta, M. K. S., Rana, A. I., \& Asad, U. (2008). Owner characteristics and health of SMEs in Pakistan. Journal of Small Business and Enterprise Development, 15(1), 130-149. Available at: https://doi.org/10.1108/14626000810850883.

Chowdhury, M. S. (2007). Overcoming entrepreneurship development constraints: The case of Bangladesh. Journal of Enterprising Communities: People and Places in the Global Economy, 1(3), 240-251. Available at: https://doi.org/10.1 108/17506200710779549.

Harvie, C. (2010). East Asian production networks - the role and contribution of SMEs. International Journal of Business and Development Studies, 2(1), 27-62.

Indarti, N., \& Langenberg, M. (2004). Factors affecting business success among SMEs: Empirical evidences from Indonesia. Second BiAnnual European Summer ...,August, 1-15.

Jamali, S., Anka, D., \& Khooharo, A. (2010). An evaluation of small and medium enterprises development in Pakistan. OIDA International Journal of Sustainable Development, 2(1), 43-50.

Kureshi, N., Qureshi, F., \& Sajid, A. (2010). Current health of quality management practices in service sector SME A case study of Pakistan. TQM Journal, 22(3), 317-329. Available at: https://doi.org/10.1108/17542731011035541.

Loewe, M., Al-Ayouty, I., Altpeter, A., Borbein, L., Chantelauze, M., Kern, M., . . . Reda, M. (2013). Which factors determine the upgrading of small and medium-sized enterprises (SMEs)? The case of Egypt. In SSRN Electronic Journal, 167-175. Available at: https://doi.org/10.2139/ssrn.2283056.

Marri, H. B., Gunasekaran, A., \& Sohag, R. (2007). Implementation of advanced manufacturing technology in Pakistani small and medium enterprises. Journal of Enterprise Information Management, 20(6), 726-739. Available at: https://doi.org/10.1108/17410390710830745.

Naqvi, S. W. H. (2011). Critical success and failure factors of entrepreneurial organizations: Study of SMEs in Bahawalpur. Journal of Public Administration and Governance, 1(2), 17-22. Available at: https://doi.org/10.5296/jpag.v 1i2.824.

Ntakobajira, N. (2013). Factors affecting the performance of small and micro enterprises (Smes) Traders At City Park Hawkers Market In Nairobi County (Vol. 65). Kenya.

OECD, \& WBG. (2015). Inclusive global value chains : Policy options in trade and complementary areas for GVC integration by small and medium enterprises and low-income developing countries.

Okpara, J. O. (2011). Factors constraining the growth and survival of SMEs in Nigeria: Implications for poverty alleviation. Management Research Review, 34(2), 156-171. Available at: https://doi.org/10.1108/01409171111102786.

Shah, A. A., Mehmood, T., Hashmi, M. A., Shah, S. M., \& Shaikh, F. M. (2011a). Performance of SMEs in export growth and its impact on economy of Pakistan. International Journal of Business and Management, 6(7), 287-297. Available at: https://doi.org/10.5539/ijbm.v6n7p287.

Shah, A. A., Mehmood, T., Hashmi, M. A., Shah, S. M., \& Shaikh, F. M. (2011b). Performance of SMEs in export growth and its impact on economy of Pakistan. International Journal of Business and Management, 6(7), 287-297.

Tambunan, T. T. H. (2011). Development of small and medium enterprises in a developing country: The Indonesian case. Journal of Enterprising Communities: People and Places in the Global Economy, 5(1), 68-82. Available at: https://doi.org/10.1108/17506201111119626.

Tonello, M. (2011). Sustainability matters: Why and how corporate boards should become involved. Paper presented at the The Conference Board Research Report. Retrieved from: https://papers.ssrn.com/sol3/papers.cfm?abstract_id=2032230.

Trovato, G., \& Alfò, M. (2006). Credit rationing and the financial structure of Italian small and medium enterprises. Journal of Applied Economics, 9(1), 167-184. Available at: https://doi.org/10.1080/15140326.2006.12040643. 